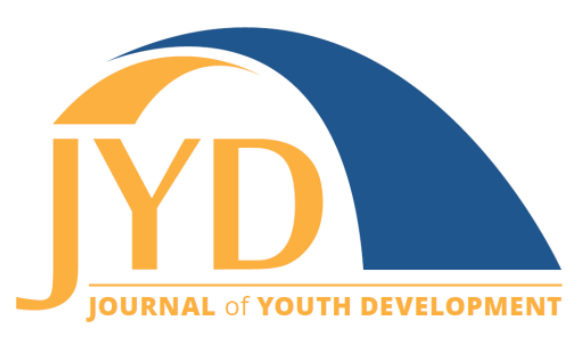

http://jyd. pitt. edu/ | Vol. 14 Issue 2 DOI 10.5195/jyd.2019.712 | ISSN 2325-4017 (online)

\title{
Immigrant Youth in Juvenile Facilities: A State-by-State Review of Recreation Programming
}

\author{
Maria León \\ Texas A\&M University, Youth Development Program \\ maria_leon@tamu.edu
}

\begin{abstract}
Recent national events have increased attention towards immigrant youth. Youth placed in juvenile justice facilities go through processes overseen by the U.S. Citizen and Immigration Services, the Office of Refugee Resettlement, and the Unaccompanied Children's Program. While in placement youth are exposed to risk factors and face cultural barriers being in a new country. As publicity of the incarceration of immigrant youth increases, there is an emphatic need for researchers to examine the quality of care youth experience in placement facilities. One of the areas that has not been critically investigated is recreation programming in juvenile justice facilities. Recreation programs grounded in Positive Youth Development have proven to promote healthy development and offer immigrant youth opportunities to adapt to their new environment. Providing youth in juvenile justice facilities access to high quality recreation programming strengthens protective factors in youth to prepare them for adulthood, and reduces the likelihood of their committing an offense, thereby increasing public safety and saving taxpayer dollars. This paper is a first step to establish a clear understanding of the treatment of immigrant youth in detention. In this paper I discuss the results of a comprehensive examination of the minimum requirements for recreation programming in juvenile justice facilities. The results provide clear implications for immigrant youth as well as suggestions for further critical inquiry.
\end{abstract}

Key words: immigrant, youth development, juvenile justice, recreation, policy

\section{Introduction}

Since May $7^{\text {th }}, 2018$ there has been increasing scrutiny of the conditions of detention centers housing immigrant children in the United States (Arnold, 2018). Journalist images and reports have raised public concern of the conditions in these facilities. There is consensus that children

(c) $\mathrm{EY}_{\mathrm{EY}}$ New articles in this journal are licensed under a Creative Commons Attribution 4.0 License. This journal is published by the University Library System, University of Pittsburgh and is cosponsored by the University of Pittsburgh Press. The Journal of Youth Development is the official peer-reviewed publication of the National Association of Extension 4-H Agents and the National AfterSchool Association. 


\section{Immigrant Youth in Juvenile Justice Facilities}

and youth in detention are exposed to negative influences that impact health and long-term well-being (The Annie E. Casey Foundation [AECF], 2015; Gonzales, Suárez-Orozco \& DediosSanguineti, 2013). The complexity of the systems immigrant youth navigate must be elucidated to create ethical and appropriate policies, procedures, and programs.

In the following pages, I will provide a critical commentary on recreation in the juvenile justice system and its impact on undocumented and immigrant youth. This paper is intended to provide youth professionals and researchers an understanding of the network of agencies immigrant youth must navigate upon arrival in the United States and share the minimum standards of recreation in juvenile justice facilities. This paper is not intended to be used as a legal resource. Unless otherwise specified, juvenile justice facility regulations are discussed in the aggregate although each state has its own procedures guiding youth placement in detention facilities.

\section{Profile of Immigrant Youth}

Immigrants between the ages of 5 and7 years make up $5.1 \%$ of the U.S. population (Migration Policy Institute, n.d.). There are 5.1 million children in the United States with at least one undocumented immigrant parent in the United States; 4.1 million (80\%) of these children were born in the United States and 809,000 (16\%) are considered undocumented (Gelatt \& Zong, 2018).

\section{Immigrant Youth Currently Incarcerated}

In the United States, states are not required to report the number of youth incarcerated to the federal level, making it difficult to determine the exact number of incarcerated undocumented youth. As of December 2017, 39,455 (21\%) of the individuals under supervision of the Federal Bureau of Prisons were identified as foreign-born (U.S. Department of Justice, 2017). At that time, there were 19,311 people identified by the U.S. Marshals Service as "under investigation" by Immigration and Customs Enforcement (U.S. Department of Justice, 2017). These figures do not include state and local immigration agencies that investigate and incarcerate immigrants.

\section{Government Systems and Agencies}

An unaccompanied immigrant child is defined as anyone under 18 years old who is without legal immigration status and has no legal parent or guardian available to provide care and 
Immigrant Youth in Juvenile Justice Facilities

custody (U.S. Department of Health \& Human Services, 2019). For the rest of this paper, I will refer to unaccompanied alien children as "children" or "youth" and use the acronym UAC, if necessary. After a child is identified as a UAC, the child's age, nationality, and immigration status is reviewed. Children and youth then go through a medical screening and assessment of their criminal record and removability, where the state has to provide evidence that the young person committed a crime or violated immigration law (Chicago Immigration Advocates Law Offices, 2019). The children are then transferred to the Office of Refugee Resettlement to determine their placement. Travel logistics are coordinated with the U.S. Immigration and Customs Enforcement and the child is transferred to the designated care provider.

Section 462 of the Homeland Security Act of 2002 transferred responsibility of care from Immigration and Naturalization Services (within the Department of Homeland Security) to the Office of Refugee Resettlement within the Department of Health and Human Services. The Unaccompanied Children's Program in the Office of Refugee Resettlement instructs that children are to be released to a sponsor who may be a parent or friend, or be referred to someone able to provide care.

U.S. Citizenship and Immigration Services (n.d.) grants Special Immigrant Juvenile Status (SIJ) to youth who cannot be placed with family. SIJ is determined by the state in court; dependency, family unification, and the youth's best interest are considered. Youth are eligible for SIJ only if they are under 21, unmarried, and have a juvenile court order. Youth who meet all of the above requirements may apply for a SIJ Visa. Only 5,000 SIJ visas are given out each year, and each country is allocated $7 \%$ (350 count) of visas granted. The process to obtain status as a "lawful permanent resident" (Green Card) can be extended if a backlog of requests causes a young person to "age out," or turn 21 before the request is processed. This was made possible in 2002, when the Child Status Protection Act was enacted to protect youth from aging out of green card eligibility by keeping their classification as a child after their $21^{\text {st }}$ birthday if they remain unmarried (UCIS, 2018).

\section{Legislation}

In 1997, the Flores Agreement was the result of a lawsuit against Immigration and Naturalization Services that established new standards for Juvenile and Family Residential Management Units. The Agreement provides that children must be placed into the least restrictive detention setting; separated from adults; transported within 72 hours; treated with dignity, respect and special concern; have access to food, water, and snacks; and be allowed 
Immigrant Youth in Juvenile Justice Facilities

visits from attorneys. These guidelines were the standard for all detention units that housed UACs until it was superseded in 2008 by the Trafficking Victims Protection Reauthorization Action (TVPRA). TVPRA includes specific guidelines for UACs to ensure protection and humane treatment for victims of trafficking.

Under TVPRA, children from contiguous countries must be screened to determine whether or not the child is a victim or at risk of being trafficked, whether there is a credible fear of persecution, and whether or not the child is able to make an independent decision for a voluntary return to its native country. Health and Human Services has 48 hours to determine if the child is a victim of trafficking or can claim asylum. Children from non-contiguous countries must be screened within 72 hours. After screening, it is decided whether or not the child meets the criteria for Special Immigrant Juvenile Status or is placed into formal removal proceedings through the Office of Refugee Resettlement. The U.S. State Department is responsible for repatriation of children from non-contiguous countries and has to make arrangements for children to be returned during daylight hours to appropriate government or welfare officials of the child's native country. If children are not coming from Canada or Mexico and placed into formal removal proceedings, Health and Human Services will be responsible for the placement of a child with family, sponsor, or in detention.

TVPRA outlines specific steps to ensure the protection of children and youth after they have been apprehended. First, once it has been determined that the child is unaccompanied, the Department of Health and Human Services must be notified within 48 hours and the youth must be transferred to Health and Human Services within 72 hours. Children will be placed in the least restrictive environment possible approved through a suitability assessment. The Executive Office for Immigration Review is required to provide legal orientations for legal custodians of children in placement. In addition, children are to have access to pro bono legal counsel and an advocate.

New proposals to amend the 2008 TVPRA have been introduced by multiple members of Congress in response to the increasing number of immigrant children entering the United States. Advocacy groups and non-profit legal organizations currently work with federal and state agencies to support immigrant youth and ensure their welfare throughout this process. Historically, positive youth development has not been directly included in these efforts. 


\section{Positive Youth Development}

Positive youth development (PYD) emphasizes that young people are assets in the making and focuses on strengthening protective factors to minimize the impact of risk factors (Catalano, Berglund, Jean, Lonczak, \& Hawkins, 2002). Youth are viewed according to their strengths and the contributions they make to their own development and community. The benefits of PYD are achievable across populations, settings, and activities. Youth success is due in part to the ecological approach used in PYD that accounts for the interacting contexts youth (Lerner \& Castellino, 2002).

Catalano et al. (2002) identified 15 features of quality youth programs that are central to program goals that promote positive youth development across all PYD programs:

1. Promotes bonding

2. Fosters resilience

3. Promotes social competence

4. Promotes emotional competence

5. Promotes cognitive competence

6. Promotes behavioral competence

7. Promotes moral competence

8. Fosters self-determination

9. Fosters spirituality

10. Fosters self-efficacy

11. Fosters clear and positive identity

12. Fosters belief in the future

13. Provides recognition for positive behavior

14. Provides opportunities for prosocial involvement

15. Fosters prosocial norms

These 15 outcomes align with the Office of Juvenile Justice and Delinquency Prevention (OJJDP) mission to "support the efforts of states, tribes, and communities to develop and implement effective and equitable juvenile justice systems that enhance public safety, ensure youth are held appropriately accountable to both crime victims and communities, and empower youth to live productive, law-abiding lives" (U.S. Department of Justice, OJJDP, n.d., Mission Statement).

Risk factors are "individual or environmental hazards that increase an individual's vulnerability to negative developmental behaviors, events, or outcomes, such as alcohol and drug abuse, 
Immigrant Youth in Juvenile Justice Facilities

early unprotected sexual activity, delinquency and violence, and school failure" (Witt \& Caldwell, 2018, p. 180. Risk factors include systemic and structural circumstances like poverty experienced by many immigrant youth and those in the juvenile justice system (Lerner \& Galambos, 1998; Roffman, Suarez-Orozco, \& Rhodes, 2003). The most prevalent individual risk factors of incarcerated youth include "mental health, personality, psychological issues, emotional-behavioral and social challenges, cognitive-intellectual development, academic achievement, victimization history, and substance use" (Pyle, Flower, Fall \& Williams, 2016, p. 180. In addition, immigrant youth are exposed to cultural barriers and discrimination more frequently (Morland, 2007; Portes \& Rumbaut, 2001).

Protective factors "buffer, modify, or ameliorate an individual's reaction to an adverse situation that, in ordinary circumstances would lead to maladaptive outcomes (Witt \& Caldwell, 2018, p. 180). Like risk factors, protective factors can be found within and outside of the individual. PYD programs enhance protective factors in and around a young person to minimize the influence of risk factors.

\section{Protective Factors}

Protective factors mitigate the impact of risk factors. PYD programs involving immigrant youth have demonstrated a positive impact on future generations, accentuating the need for PYD recreation programs in juvenile justice facilities (Portes \& Rumbaut, 2001).

The foundation of PYD programs is the physical and psychological safety of youth (Eccles \& Gootman, 2002; Rossiter \& Rossiter, 2009). Dr. Nadine Burke Harris explained that adverse childhood experiences produce toxic stress that limit the brain's ability to think and can have long-term health implications if they go unaddressed (Garrett, 2014). When youth do not believe they are safe, the brain releases cortisol, increasing fear and inhibiting a young person's ability to develop trust (National Scientific Council on the Developing Child [NSCDC], 2014). Recreation programs have a unique opportunity to address this neurological phenomenon through meaningful relationships that are fostered among youth and adults in a nonconfrontational manner.

Rossiter and Rossiter (2009) identified specific protective factors for immigrant youth at the family, individual, peer, school, and community levels. Immigrant youth who live with both parents that are financially secure, able to be home and have knowledge of the school system their children are in have reported better outcomes (Rossiter \& Rossiter, 2009). A sense of 
Immigrant Youth in Juvenile Justice Facilities

belonging, cultural identity, and involvement in community organizations that promote education and career development are all cited as protective factors for immigrant youth (Rossiter \& Rossiter, 2009). Programs are most effective when they incorporate aspects of the young person's culture and heritage (Morland, 2007).

The connection youth have with adults is a determinant of their ability to adapt; youth from collectivist cultures assume the role of a contributor in the family, influencing the family's overall adjustment (Burgos, Al-Adeimi, \& Brown, 2017; Catalano et al., 2002). The psychological well-being of immigrant youth is linked to their ability to support their family through transition and instability (Burgos, Al-Adeimi, \& Brown, 2017). Removing immigrant youth from their family compounds existing challenges, and the fear of being removed or having a parent removed is detrimental to the health and well-being of youth (Yoshikawa, Suárez-Orozco \& Gonzales, 2016).

Recreation programs can address risk factors if they are properly planned and staff is trained to respect all young people regardless of their nationality. Youth-centered relationships provide emotional and instrumental support marked by warmth, connectedness, stability, respect and communication to produce successful long-term outcomes (Eccles \& Gootman, 2002). Evidence suggests youth learn how to commit crimes when they are in detention with other young people, another caution in detaining immigrant youth in juvenile justice facilities. In fact, youth grouped together with the intention of addressing a problem behavior have demonstrated an increase in problem behaviors (Eccles \& Gootman, 2002). Delinquency is decreased when programs are structured and provide supervision; guidelines are most effective when consistent across the contexts a young person occupies (Eccles \& Gootman, 2002; Weinstein, Fuller, Mulrooney, \& Koch, 2014). Immigrant youth moved between settings are faced with the task of reconciling cultural differences in addition to different facility rules. Juvenile recreation programs must recognize the cultural background of immigrant youth to promote healthy development of youth in placement (Morland, 2007).

Positive youth development recreation programs create an environment that is developmentally appropriate and responsive to the needs and maturity of young people (Morland, 2007; Portes \& Rumbaut, 2001; Yoshikawa et al., 2016). Resiliency is a protective factor that can prevent youth from adopting problem behaviors while they are in detention and is a key indicator of acculturation (Catalano et al., 2002; Motti-Stefanidi, 2018). Resiliency is promoted through scaffolding, a practice that requires adults to provide support to young people as youth are presented challenges of increasing difficulty as their skills develop (Morgan, Sibthorp, \& Wells, 
2014). When young people accomplish tasks they perceive as challenging, they develop a healthy sense of autonomy. Preparing immigrant youth to access resources in the new environment is key to successfully transitioning into adulthood (Chung, Little \& Steinberg, 2005).

Developing programs with structure and guidelines that are culturally appropriate and have congruent values with the community context will improve youth outcomes. Recreation programs as a context for promoting positive youth development in juvenile justice facilities in the United States will be the subject of the remainder of this paper.

\section{Methods}

A systematic review was conducted in the spring of 2017 of the recreation guidelines in juvenile justice facilities' written authorities for each state. Data were collected from respective juvenile justice websites and legal research databases, Thomson Reuters Westlaw and Lexis Nexis Academic. A survey was used to screen each written authority on 17 items and exported for analysis using Microsoft Excel.

The elements screened for included:

- Agency/department affiliation

- Type of written authority

- Stated purpose of recreation program (presence and content)

- Terms used in the written authority

- Definitions used for recreation, leisure \& exercise, if available

- Daily or weekly mandatory minimum of time for recreation

- Staffing qualifications, if specified

- Specific activities

- Prohibited activities

- Location for activities

- Outdoor time

- Exceptions to providing recreation services

- Special guidelines for weekends and holidays 


\section{Limitations}

This study was limited to the 50 states in the United States, not including U.S. territories and includes only information available at the time of data collection. This study is not a review of fidelity between the guidelines and implementation. All juvenile justice facilities are included regardless of security or facility type since these differences are not recognized in the documents. There are states that contract out residential care for youth in the juvenile justice system to facilities that share guidelines with foster care and other out-of-home placements. This study includes all possible facilities that can house immigrant youth, not just facilities that have previously housed or currently house immigrant youth. Minimum guidelines for private facilities were not included in this study.

\section{Results}

\section{Agency Affiliation}

Figure 1 shows over half of U.S. states house juvenile justice facilities in Health and Human Services and Juvenile Justice. Twelve independent state agencies were found in this study, although states may have an Office or Commission for juvenile justice within larger departments.

\section{Figure 1. Juvenile Justice Facility Agency Affiliation}

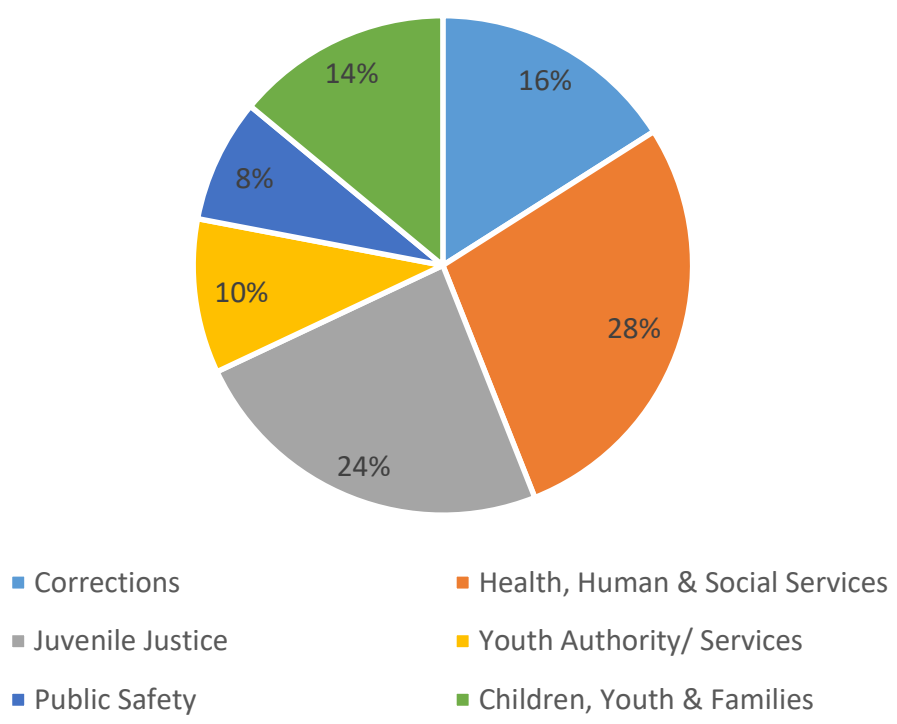


Figure 2 shows $10 \%$ of states have approved standards for juvenile facilities, $8 \%$ cite standards from external organizations, and $4 \%$ of states designate individual facilities to establish their own guidelines. Four percent of states include guidelines for recreation in the administrative code, the highest written authority. Thirty-four percent of states do not have a written authority that has been approved by a legislative body and carries legal consequences.

\section{Figure 2. Types of Written Authorities}

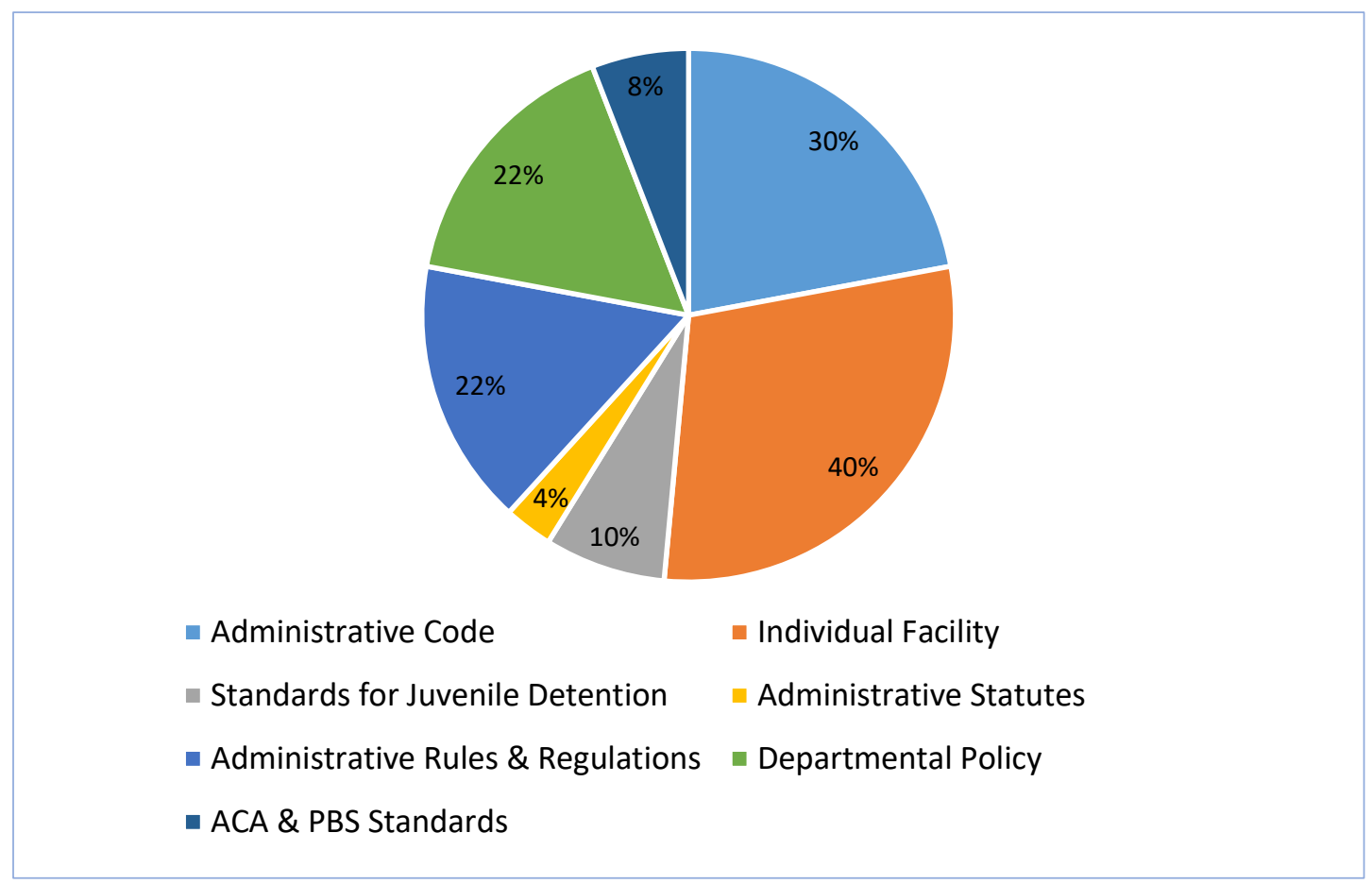

\section{Written Authorities}

A key discovery is the range of terms used in different states to describe the guidelines for recreation in juvenile facilities shown in Figure 2. Terms included: administrative codes, standards, regulations, rules, policies, and laws. The variation indicates differences in legal weight. To add complexity, terms are not necessarily equivocal across states.

Forty percent of states include a purpose statement in their written authority (60\% do not). The presence or absence of a purpose statement is indicative of the value that states place on quality recreation programs. Table 1 lists the themes found after coding the purpose statements. Of the states with a purpose statement, $65 \%$ cite health and wellness, and $35 \%$ cite character development. 


\section{Type}

The type of recreation is the nature of activities; Table 1 presents a breakdown of types. Physical exercise and active activities were mentioned by 19 states. Leisure or passive activities are identified in 15 written authorities.

Table 1. Types of Activities Described in Written Authorities

\begin{tabular}{|l|l|c|}
\hline Type of activity & States & $\%$ \\
\hline Physical Ewercise/Active activities & AK, AR, CA, KY, LA, MA, MI, MT, NC, ND, & $38 \%$ \\
\hline Leisure/Passive activities & NE, NV, OH, SC, TN, UT, VT, WI, WV & \\
\hline Games & TN, WV, WI, WY, MT & \\
\hline Arts \& crafts, creativity & $\mathrm{KS}, \mathrm{MD}, \mathrm{NM}, \mathrm{NY}, \mathrm{IA}$ & $10 \%$ \\
\hline Group & $\mathrm{IA}, \mathrm{KS}, \mathrm{MD}, \mathrm{WY}$ & $8 \%$ \\
\hline Individual & $\mathrm{MD}, \mathrm{NH}, \mathrm{NM}, \mathrm{VA}$ & $8 \%$ \\
\hline Quiet activity & $\mathrm{MD}, \mathrm{NH}, \mathrm{VA}$ & $6 \%$ \\
\hline Competitive & $\mathrm{MD}, \mathrm{NM}, \mathrm{NY}$ & $6 \%$ \\
\hline Non-Competitive & $\mathrm{GA}, \mathrm{NM}$ & $4 \%$ \\
\hline Adapted & $\mathrm{CO}, \mathrm{GA}$ & $4 \%$ \\
\hline Reading (books, magazines) & $\mathrm{MD}$ & $2 \%$ \\
\hline TV (regulations on news programming \& movies) & $\mathrm{CA}$ & $2 \%$ \\
\hline Music & $\mathrm{CA}$ & $2 \%$ \\
\hline Video games & $\mathrm{CA}$ & $2 \%$ \\
\hline Improve exposure to different opportunities & $\mathrm{DE}$ & $2 \%$ \\
\hline Healthy living & $\mathrm{MA}$ & $2 \%$ \\
\hline Social awareness & $\mathrm{CA}$ & $2 \%$ \\
\hline
\end{tabular}

\section{Terms and Definitions}

Three terms in written authorities arose frequently throughout the screening process: recreation, exercise and leisure. To understand the meaning of terms, documents were screened for definitions. Figure 3 shows how many states used each term and how many provided definitions. 
Figure 3. Number of States With and Without Definitions of Terms

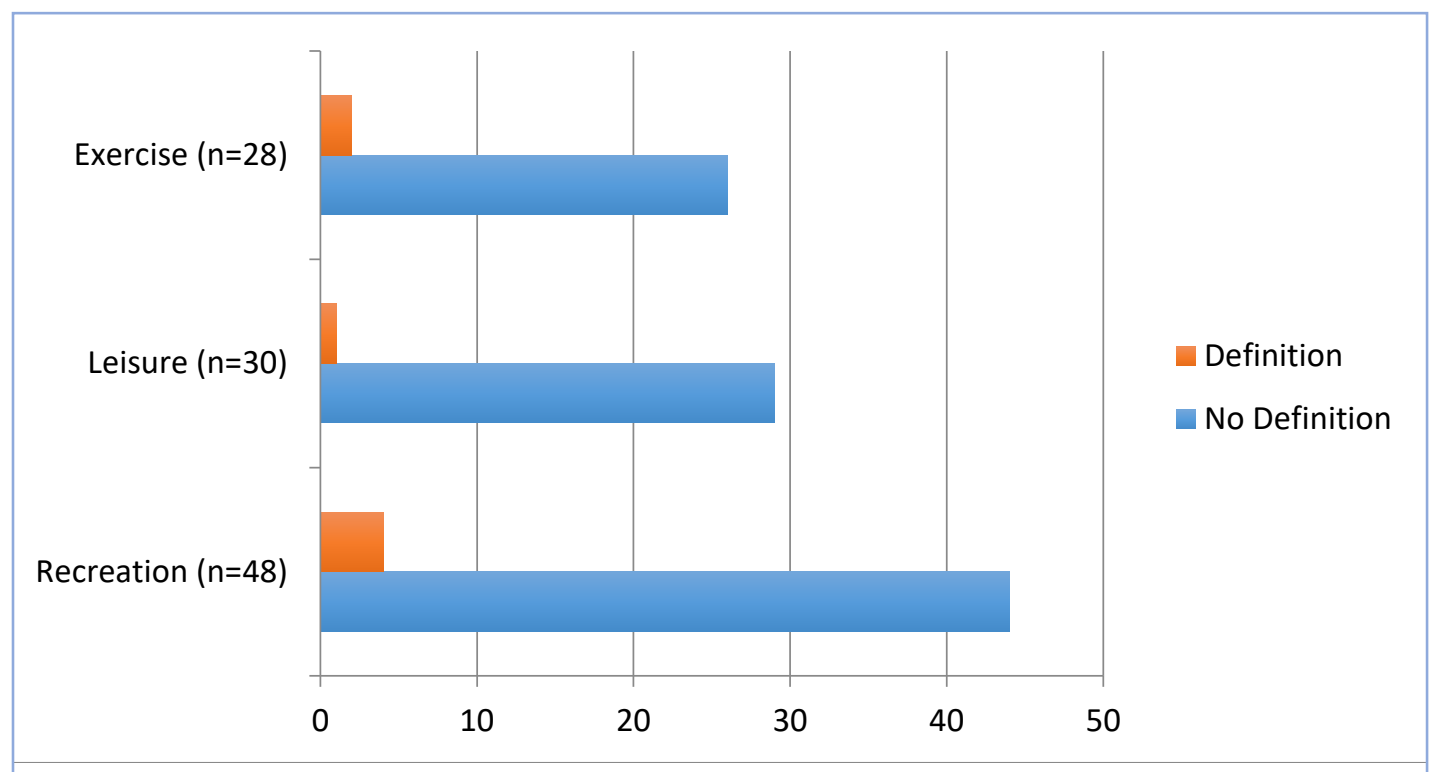

\section{Frequency}

Frequency is how often states offer recreation to youth. Ten states do not specify a required minimum amount of recreation time to be offered in juvenile facilities; it is possible these states contract out care to facilities with their own requirements. Figure 4 shows the breakdown of states according to frequency, including five states that have a weekly minimum instead of daily.

Figure 4. Frequency of Recreation Programming

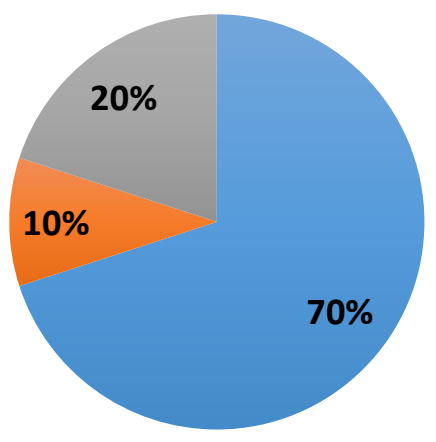

Daily

Weekly

Not Specified 


\section{Duration}

Thirty-five states include a minimum amount of time each day during which recreation access must be provided. On average, youth in juvenile facilities are given 1.68 hours per day of recreation, with $46 \%$ of states requiring two hours. Figure 5 displays minimum hours required and Table 2 shows time allotted for particular activities.

Figure 5. Number of States With Minimum Durations of Recreation Activity

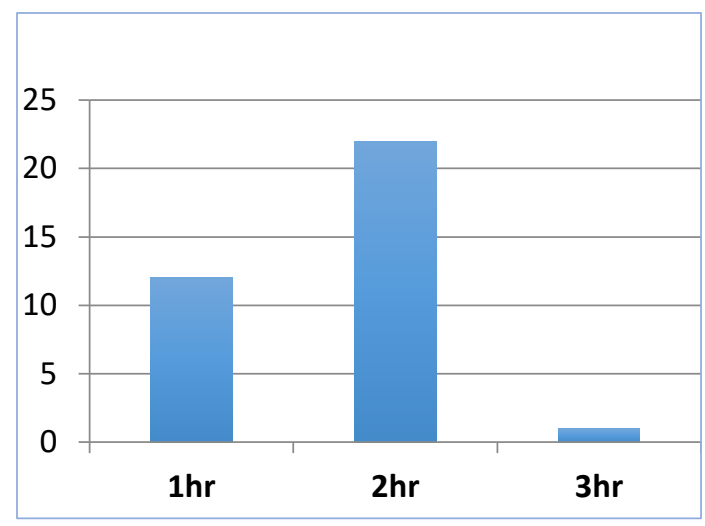

Table 2. Time Specifications for Activities

\begin{tabular}{|l|c|}
\hline Activity & $\%$ of states \\
\hline 1 hour Large Muscle Activity/Exercise (LMA/LME) & $46 \%$ \\
\hline 1 hour unstructured/ leisure & $42 \%$ \\
\hline 1 hour active/open/ out of cell & $8 \%$ \\
\hline 30 minutes gross motor & $2 \%$ \\
\hline 90 minutes major muscle group & $2 \%$ \\
\hline
\end{tabular}

\section{Exceptions}

As part of this review, I screened reasons why youth would be denied access to recreation. Table 3 shows the exceptions that were identified. Fifty-six percent of states included at least one exemption. The parameters and guidelines used to determine exemptions must be investigated to ensure decisions are not based on the bias of the facility staff. The "loss of privilege" exception raises the question of whether or not recreation is a privilege or right, especially for youth immigrants. The World Health Organization guidelines recommend children 
and youth between the ages of 5 and 17 spend at least 60 minutes of moderate to vigorousintensity activity daily (2018). Advocates and policy makers are recognizing the developmental processes occurring during adolescence and the detrimental impact confinement has on young people, including the development or exacerbated mental health problem, demonstration of anti-social behavior, self-harm, and attempts at suicide (Scialabba, 2016).

Table 3. Exceptions to Recreation Programming $(n=28)$

\begin{tabular}{|l|c|}
\hline Exception & \% of states \\
\hline Security & $38 \%$ \\
\hline Weather & $30 \%$ \\
\hline Medical/ Health & $26 \%$ \\
\hline Safety & $10 \%$ \\
\hline Discipline & $8 \%$ \\
\hline Behavior & $6 \%$ \\
\hline Segregation/ Isolation & $4 \%$ \\
\hline
\end{tabular}

\section{Discussion}

The results indicate numerous challenges to evaluate recreation programs in U.S. juvenile justice facilities. The inability to conduct evaluations of implementation limits confidence in the quality of care for youth. Thirty-four percent of states do not have a written authority that has been approved by a legislative body that has a legal effect. This alone limits the accountability for recreation programs.

After analyzing the written authorities for each of the 50 states, three primary conclusions appear:

1. Inconsistency across and ambiguity within written authorities prevents best practices from being established and monitored.

2. Benefits of recreation and leisure programming for immigrant youth are not understood.

3. There is a need for increased communication between agencies. 
Immigrant Youth in Juvenile Justice Facilities

\section{Inconsistency Across and Ambiguity Within Written Authorities Prevents Best Practices From Being Established and Monitored}

Inconsistency and ambiguity in written authorities limits the comparability of requirements, implementation and outcomes of recreation programs in juvenile justice facilities across states. The results show no centralized guidelines for recreation in juvenile justice facilities as only four states cite the American Correctional Association as their authority. The range of agencies, themes, and activities identified in the documents prevent best practices and accountability from being established. Without best practices and legal provision for guidelines outlined in written authorities, the Office of Refugee Resettlement cannot guarantee ethical, developmentally appropriate conditions for immigrant youth in custody.

The lack of specificity outlining activities and conditions of recreation programs puts pressure on the facility staff to provide programming. Seventeen states have a provision for a designated recreation staff person and eight states include qualifications. Of the staff that are appointed to direct recreation programs, $60 \%$ of states have a purpose statement and four states have a definition of recreation to guide their planning. Without a clear mission and purpose including program objectives and definitions, it is difficult to build high quality programs that can be evaluated. Without evaluations of programs, there is no guarantee of the quality of program.

\section{Benefits of Recreation and Leisure Programming for Immigrant Youth Are Not Understood}

These results have implications for all youth placed in a juvenile justice facility, specifically immigrant youth who benefit from PYD programs (Stodolska \& Camarillo, 2018). The benefits of quality recreation programming are not understood or appreciated by those who create the guidelines and written authorities as evidenced by limited definitions and the absence of legal consequences and absent purpose statements. The burden of producing recreation programs falls to facility staff. Given the negligible attention it receives in written authorities, it is unlikely that the benefit is prioritized or allocated sufficient resources. Front-line staff are often given limited or no information regarding a young person's offense, leaving immigrant youth that have not committed a crime exposed to the maltreatment all youth endure in correctional settings (AECF, 2015). 
Immigrant Youth in Juvenile Justice Facilities

\section{There Is a Need for Increased Communication Between Agencies}

In order for effective change to take place and have a positive impact on immigrant youth in the juvenile justice system, there must be communication between actors. Seven types of written authorities that come from six different departments and agencies were discovered and screened. In order to promote best practices for recreation in juvenile justice facilities, agencies and departments need to communicate.

In 14 states juvenile justice agencies are housed in Health, Human and Social Services, the federal agency that handles immigrant youth. In order for immigrant youth in detention to be adequately supported at the state and local levels, clarity is needed to explain the immigration process for youth to become citizens. Increasing effective communication between state and federal agencies must be a priority for agencies and departments that deal with immigrant youth.

\section{Recommendations}

Initial changes must begin with increasing transparency of the placement process and standards of care in placement settings. States should outline the process by which immigrant youth are placed in a juvenile justice facility and include the standards of care- - similar to a youth rights handbook -and make it accessible to youth and the public.

The Juvenile Justice Delinquency and Prevention Act (JJDPA) was reauthorized in December 2018 for the first time since 2002 after being established in 1974. The reauthorization emphasizes the elimination of dangerous practices and improved conditions for youth in confinement. There are new requirements for local and state facilities to report data to OJJDP. The data collected serve as a benchmark of the quality of conditions for youth in confinement. As the conditions of confinement for youth improve, recreation will be scrutinized. I appeal to professionals, researchers and policy makers to consider the results of this study in light of the JJDPA.

\section{Research}

Recreation and youth development researchers must seize the opportunity to address the maltreatment of youth in the juvenile justice system; it is ineffective and it negatively impacts youth and communities. Recreation and leisure scholars should communicate the significance of 
Immigrant Youth in Juvenile Justice Facilities

leisure across the lifespan and the cost-effectiveness of community recreation programs. In addition to increasing positive outcomes for all young people, it should be emphasized that PYD recreation programs have proven to be particularly effective with immigrant youth and those involved in the juvenile justice system.

Migration studies experts have theorized the acceptability of the detainment of immigrants. The findings of this study corroborate the position that the immigration system resembles the criminal justice system. The frameworks provided by migration studies call attention to how immigrant youth are criminalized and not afforded appropriate opportunities for recreation.

Policies and programs must be evaluated for the suitability of immigrant youth. One-pager policy recommendations should be made based on developmental theory. Agency processes that immigrant youth navigate must be critically examined and reformed to match the needs and competencies of youth and avoid compounding trauma for youth.

Each city, county, and state has its own set of procedures and relationship with federal agencies like the Office of Refugee Resettlement and Immigration and Customs Enforcement. The treatment and outcomes for youth should be evaluated and compared. In evaluations, researchers should pay attention to disparities among immigrant youth based on age, country of origin, gender, education level, ability, etc.

In addition to sharing the results of research with policy makers and professionals, information needs to be communicated to the general public. Voters need to be provided with accurate information about the experiences of immigrant youth. Communities need to be provided knowledge that will allow them to partner with organizations and agencies to effectively support immigrant youth.

\section{Policy}

Policy makers need to review the minimum recreation requirements for youth in juvenile justice facilities outlined in the written authority in each state. If one does not already exist, a youth rights handbook should be created, updated and made accessible to the public. It should include the process for immigrant youth to obtain citizenship, including the required documentation and timelines. 
Immigrant Youth in Juvenile Justice Facilities

Policy makers should seek recommendations from researchers and request one-pagers relevant to the decisions that they vote on. Policy makers should ensure that there is accountability built into the policies through reporting measures that ensures children are placed in the least restrictive possible setting. Working directly with youth, practitioners, and researchers to create policy will increase the fidelity and developmental appropriateness. Policy makers should examine the relationship that lobbying groups have with the private prison system and identify ethical issues that would result from the outcome of a political decision.

\section{Practice}

Professionals that work with youth need to be familiar with the immigration system for youth. It is important that this material is accessible to youth and written in a language that youth understand and using pictures and graphics when appropriate. Equipping young people with the ability to advocate for themselves is an important step to ensuring their safety as they move throughout social service systems. Immigration lawyers can be invited to the facility to answer questions and provide youth with information regarding their rights and pathways to citizenship.

Recreation staff in juvenile justice facilities need to be given training and support to structure programs and activities with a PYD framework. Recreation staff need to be considered essential members of the treatment team and look for ways to integrate the cultures of immigrant youth into the recreation program (Morland, 2007). In addition to PYD training, staff should be educated on the specific considerations for working with immigrant youth and the significant impact PYD recreation programs can have for this population.

A major concern regarding the safety of immigrant youth that was not addressed in this paper is the connection to human trafficking. Recreation programs have the potential to draw abusers under the guise of a caring adult. It is imperative to ensure that staff and volunteers complete a background check process and have only supervised access to young people. Specifically, in facilities that house immigrant youth, recreation staff should be trained to recognize the signs of trafficking with instructions for reporting suspected trafficking. Another component of programs not addressed here is ensuring cultural competence in recreation programs. Staff should be trained to respect all youth and their respective backgrounds. 


\section{Conclusion}

It is the intention of this paper to expose the process of immigrant youth being placed in juvenile justice settings and examine the conditions of their treatment, specifically analyzing recreation programs and highlighting how they can promote PYD. The current status of recreation programming according to the written authorities for each state indicates that recreation is not considered a vital component of the treatment process. With the increased media attention on the welfare and treatment of immigrant youth, specifically along the southern U.S. border, it is time that policy makers, professionals, and researchers critically assess the conditions of juvenile justice facilities in which immigrant youth are placed. The impact of how youth are treated in these facilities will have immediate and long-term consequences if attention is not given and issues addressed.

Recreation offers a viable launch point for humanizing the juvenile justice system with which immigrant youth come in contact. The results of this study invite multiple perspectives to continue the investigation at a policy and practice level. In order for improvements to be successful, researchers, policy-makers and practitioners will need to collaborate and hold each other accountable. Providing the public with accurate, up-to-date information regarding the implementation of policy is ethical and increasingly important in such a polarized political climate. Changes to the systems that incarcerate youth are necessary and long overdue. It should be the goal of all people concerned with the well-being and future of youth in this country to advocate on behalf of a group of the most vulnerable children and youth in our society.

\section{References}

The Annie E. Casey Foundation. (2015). Maltreatment of youth in U.S. juvenile corrections facilities. Baltimore, MD: Mendel, R. Retrieved from https://www.aecf.org/resources/maltreatment-ofyouth-in-us-juvenile-corrections-facilities/

Arnold, A. (2018, June 21). What to know about the detention centers for immigrant children across the U.S.-Mexico Border. Family Separation Policy. The Cut. Retrieved from https://www.thecut.com/2018/06/immigrant-children-detention-center-separated-parents.html

Burgos, M., Al-Adeimi, M., \& Brown, J. (2017). Protective factors of family life for immigrant youth. Child \& Adolescent Social Work Journal, 34(3), 235-245. doi:10.1007/s10560-016-0462-4

Catalano, R. F., Berglund, M. L., Ryan, J. A. M., Lonczak, H. S., \& Hawkins, J. D. (2004). Positive youth development in the United States: Research findings on evaluations of positive youth 
Journal of Youth Development | http://jyd.pitt.edu/ | Vol. 14 Issue 2 DOI 10.5195/jyd.2019.712

Immigrant Youth in Juvenile Justice Facilities

development programs. The Annals of the American Academy of Political and Social Science 5(1), 98-124. doi:10.1037//1522-3736.5.1.515a

Chicago Immigration Advocates Law Offices. (2019). Inadmissibility vs removability. Retrieved from https://chicagoimmigrationlawyers.net/about-deportation/inadmissibility-vs-removability/

Chung, H. L., Little, M., \& Steinberg, L. (2005). The transition to adulthood for adolescents in the juvenile justice system: A developmental perspective. In D. W. Osgood, E. M. Foster, C. Flanagan, \& G. R. Ruth (Eds.), The John D. and Catherine T. MacArthur Foundation Research Network on Transition to Adulthood. On your own without a net: The transition to adulthood for vulnerable populations (pp. 68-91). Chicago, IL: University of Chicago Press.

Eccles, J. S., \& Gootman, J. A. (2002). Community programs to promote youth development. Washington, DC: National Academy Press.

Garrett, K. (2014). Childhood trauma and its affects on health and learning. The Education Digest, 79(6), 4-9.

Gelatt, J., \& Zong, J. (2018). Settling in: A profile of the unauthorized immigrant population in the United States. Washington, DC: Migration Policy Institute.

Gonzales, R. G., Suárez-Orozco, C., \& Dedios-Sanguineti, M. C. (2013). No place to belong: Contextualizing concepts of mental health among undocumented immigrant youth in the United States. American Behavioral Scientist, 57(8), 1174-1199.

Lerner, R. M., \& Castellino, D. R. (2002). Contemporary developmental theory and adolescence: Developmental systems and applied developmental science. Journal of Adolescent Health, 31(6), 122-135.

Lerner, R. M., \& Galambos, N. L. (1998). Adolescent development: Challenges and opportunities for research, programs, and policies. Annual Review of Psychology, 49, 413-446. doi:10.1146/annurev.psych.49.1.413 doi:10.1146/annurev.psych.49.1.413

Migration Policy Institute. (n.d.). U.S. Immigration Trends. Retrieved from: https://www.migrationpolicy.org/programs/data-hub/us-immigration-trends

Morgan, C., Sibthorp, J., \& Wells, M. S. (2014). Fun, activities, and social context: Leveraging key elements of recreation programs to foster self-regulation in youth. Journal of Park \& Recreation Administration, 32(3), 74-91.

Morland, L. (2007). Promising practices in positive youth development with immigrants and refugees. The Prevention Researcher, 14(4), 18-21.

Motti-Stefanidi, F. (2018). Resilience among immigrant youth: The role of culture, development and acculturation. Developmental Review, 50, 99-109. doi:10.1016/j.dr.2018.04.002

National Scientific Council on the Developing Child. (2005/2014). Excessive stress disrupts the architecture of the developing brain: Working paper No. 3. Updated edition. Retrieved from https://developingchild.harvard.edu/resources/wp3/ 
Journal of Youth Development | http://jyd.pitt.edu/ | Vol. 14 Issue 2 DOI 10.5195/jyd.2019.712

Immigrant Youth in Juvenile Justice Facilities

Portes, A., \& Rumbaut, R. (2001). Legacies: The story of the immigrant second generation. Berkeley: University of California Press.

Pyle, N., Flower, A., Fall, A. M., \& Williams, J. (2016). Individual-level risk factors of incarcerated youth. Remedial \& Special Education, 373), 172-186. doi:10.1177/0741932515593383

Roffman, J. G., Suarez-Orozco, C., \& Rhodes, J. E. (2003). Facilitating positive development in immigrant youth. In F. A. Villarruel, D. F. Perkins, L. M. Borden, \& J. G. Keith (Eds.), Community youth development: Programs, policies, and practices (pp. 90-117).

Rossiter, M. J., \& Rossiter, K. R. (2009). Diamonds in the rough: Bridging gaps in supports for at-risk immigrant and refugee youth. Journal of International, 104), 409. doi:10.1007/s12134-0090110-3

Scialabba, N. (2016). Making the case to end solitary confinement for juveniles. Children's Rights Litigation, 18(4), 9-14. Retrieved from https://www.americanbar.org/groups/litigation/committees/childrensrights/articles/2016/making-case-end-solitary-confinement-juveniles/

Stodolska, M., \& Camarillo, L. N. (2018). Leisure and recreational sport among immigrant youth. In P. A. Witt \& L. L. Caldwell (Eds.) Youth development: Principles and practices in out-of-school time settings, (pp. 517-543). Urbana, IL: Sagamore-Venture. Retrieved from https://www.researchgate.net/profile/Peter_Witt5/publication/323389633_Youth_Development_P rinciples_and_Practices_in_Out-of-

School_Time_Settings/links/5abe51a645851584fa719e3b/Youth-Development-Principles-andPractices-in-Out-of-School-Time-Settings.pdf?origin=publication_detail

U.S. Citizenship and Immigration Services. (n.d.). Child status protection act (CSPA). Washington D.C.: U.S. Citizenship and Immigration Services. Retrieved from U.S. Department of Homeland Security website: https://www.uscis.gov/greencard/child-status-protection-act

U.S. Department of Health \& Human Services. (2019). About unaccompanied alien child program. Retrieved from https://www.acf.hhs.gov/orr/programs/ucs/about

U.S. Department of Justice, Office of Juvenile Justice and Delinquency Prevention. (n.d.). Mission statement. Retrieved from https://www.ojjdp.gov/about/missionstatement.html

U.S. Department of Justice, Office of Public Affairs. (2017, December 21). Departments of Justice and Homeland Security release data on incarcerated aliens-94 Percent of all confirmed aliens in DOJ custody are unlawfully present. Retrieved from https://www.justice.gov/opa/pr/departmentsjustice-and-homeland-security-release-data-incarcerated-aliens-94-percent-all

Weinstein, M. B., Fuller, K., Mulrooney, T., \& Koch, G. (2014). The benefits of recreational programming on juvenile crime reduction: a review of literature and data. 9/2/2014, National Recreation and Parks Association. Retrieved from http://www.nccu.edu/formsdocs/proxy.cfm?file_id=2907 
Journal of Youth Development | http://jyd.pitt.edu/ | Vol. 14 Issue 2 DOI 10.5195/jyd.2019.712 Immigrant Youth in Juvenile Justice Facilities

Witt, P. A., \& Caldwell, L. L. (2018). Youth development: Principles and practices inoOut-of-school time settings. Urbana, IL: Sagamore-Venture.

World Health Organization. (2018). Physical activity. (Fact sheet No. 385). Retrieved from http://www.who.int/mediacentre/factsheets/fs385/en/

Yoshikawa, H., Suárez-Orozco, C., \& Gonzales, R. G. (2017). Unauthorized status and youth development in the United States: Consensus statement of the society for research on adolescence. Journal of Research on Adolescence, 271), 4-19. doi:10.1111/jora.12272 